\title{
Understanding the attitudes towards mental illness among graduate students at a small midwestern religious college
}

Jennifer Grodsky ( $\boldsymbol{\sigma}$ jennifer.grodsky@alverno.edu )

Alverno College https://orcid.org/0000-0002-8618-7763

Kendra Bittner

Alverno College

Shara Alvarado

Alverno College

\section{Research Article}

Keywords: stigma, mental health, students, community psychology

Posted Date: September 15th, 2021

DOl: https://doi.org/10.21203/rs.3.rs-905630/v1

License: (c) (i) This work is licensed under a Creative Commons Attribution 4.0 International License.

Read Full License 


\section{Abstract}

Objective: To describe college students', specifically health care professionals in-training, attitudes towards individuals diagnosed with mental illness.

Participants: Graduate students $(n=214)$ at a small midwestern college. Sixty-two percent enrolled in community psychology; $38 \%$ in nursing; and $30 \%$ from other graduate programs. Almost all were female (97\%) and white (70\%).

Methods: A cross-sectional electronic survey design

Results: Community psychology students had significantly more empathy towards individuals with mental illness then other graduate students $(p<0.05)$. Other graduate students $(p=0.04)$ and nursing students $(p=0.010)$ had significantly more acceptance toward deinstitutionalization as compared to community psychology students. Those who indicated higher levels of individual knowledge and personal experience with mental illness had less stigma and pessimistic attitudes $(p \leq 0.05)$.

Conclusions: Health care professionals in-training have underlying stigma regarding individuals diagnosed with mental illness. It is imperative for our institutions of higher learning to provide educational opportunities to help decrease this stigma.

\section{Introduction}

Nationwide there is an epidemic of discrimination and stigma associated with identifying and treating people with mental illness ${ }^{1}$. When looking at stigma and mental health there is a "sense of shame," and with it also "a sign of weakness"2. Mental health stigma has become a trigger for adversity for many individuals seeking treatment ${ }^{2}$. Stigma has been defined as, "a product of disgrace that sets a person apart from others" ${ }^{3}$. Unfortunately, stigmatizing views about mental illness are not limited to members of the general public; even well-trained professionals from most mental health disciplines subscribe to stereotypes about mental illness ${ }^{4,5}$.

Due to the stigma associated with individuals with a diagnosis of mental health many researchers in the field of psychology have created and examined possible ways to reduce or avoid mental health stigmas. One of the most promising solutions for decreasing stigma is training health care professionals by creating multicultural courses or imbedding materials within college-level courses aimed at increasing awareness and skills when treating individuals diagnosed with mental illness ${ }^{6,7}$. Boysen and Vogel specifically focused on assessing the multicultural competencies and implicit bias of counselor trainees. Their study found significant implicit bias among a sample of counselor trainees suggesting that the trainees had the presence of implicit bias when working with their diverse clients ${ }^{6}$.

Moreover, individuals who are living with a mental health diagnosis may internalize their negative attitude towards mental illness which may lead them not to seek treatment ${ }^{2}$. Due to the stigma around mental 
health from the general population, this has caused individuals within the population to have some sort of bias toward mental illness ${ }^{8}$. One study showed that individuals who had mental health training compared to those who did not, "showed more positive implicit and explicit evaluations of people with mental illness" 8 .

One of the primary objectives of graduate programs in Community Psychology at the Midwest institution where this study was conducted was to "emphasize health and community involvement in prevention, intervention and treatment of mental health issues". The program believes that it is imperative to be able to train students to identify mental illness and overcome any personal stigma they might have. The purpose of this study was to evaluate the attitudes towards mental illness among graduate students at a small Midwestern University. More specifically to see if there were differences among students enrolled in the Community Psychology Counseling program that is focused on education to overcome some of the stigma associated with mental illness as compared to their graduate student counterparts.

\section{Materials And Methods}

We utilized a cross-sectional survey design for this study. We administered an electronic survey in the Spring of 2018 to all graduate students in the departments of community psychology, education, business, and nursing from a small, Midwestern University. We gained permission to use students email from the program deans. We contacted the students up to three times to remind them to complete the survey. The survey included basic demographic questions and a modified version of the valid and reliable Community Attitudes Toward the Mentally III (CAMI) questionnaire about personal attitudes towards mental illness". The CAMI is a valid and reliable tool that is "freely granted to use for research, educational, academic and professional purposes". The CAMI uses four subscales (Authoritarian, Social restrictiveness, Benevolence, and Community Mental Health Ideology) measured on a 5-point Likert scale ranging from 1-strongly disagree to 5 -strongly agree to assess attitudes toward individuals diagnosed with mental illness ${ }^{9}$.

Statistical analysis was completed in SPSS ${ }^{10}$. We used descriptive statistics to summarize the data. Chisquare analysis was used for dichotomous variables and t-test/ANOVAs was used for continuous variables. A p-value of less than or equal to 0.05 was considered significant. IRB approval was obtained for this study.

\section{Results}

A total of 214 out of 600 graduate students completed the electronic survey; a $36 \%$ response rate. Sixty two percent of respondents were from the community psychology program; $38 \%$ from the graduate nursing program; and $30 \%$ from 'other' graduate programs (education, nursing, and business). Almost all the respondents were female $(97 \%)$ and white $(70 \%)$. 
Table 1: Demographics

\begin{tabular}{|c|c|c|c|c|}
\hline & All & Community Psychology & Other ${ }^{n}$ & Nursing \\
\hline Total graduate enrollment, 2018 & 600 & 104 & 496 & 215 \\
\hline$n(\%)$ & $214(36 \%)$ & $64(62 \%)$ & $150(30 \%)$ & $82(38 \%)$ \\
\hline \multicolumn{5}{|l|}{ Gender } \\
\hline Female & $206(97 \%)$ & $60(94 \%)$ & $146(97 \%)$ & $82(100 \%)$ \\
\hline \multicolumn{5}{|l|}{ Race } \\
\hline White & $148(70 \%)$ & $42(66 \% 6)$ & $106(71 \%)$ & $62(77 \%)$ \\
\hline African American & $24(11 \%)$ & $10(15 \%)$ & $14(9 \%)$ & $6(7 \%)$ \\
\hline Asian & $10(5 \%)$ & $2(3 \%)$ & $8(5 \%)$ & $4(5 \%)$ \\
\hline Other & $32(15 \%)$ & $10(15 \%)$ & $20(13 \%)$ & $10(12 \%)$ \\
\hline \multicolumn{5}{|l|}{ Age Group (years) } \\
\hline $20-29$ & $56(26 \%)$ & $24(38 \% 6)$ & $32(21 \%)$ & $18(22 \%)$ \\
\hline $30-39$ & $78(36 \%)$ & $18(28 \%)$ & $60(40 \%)$ & $36(44 \%)$ \\
\hline $40-49$ & $48(22 \%)$ & $12(19 \%)$ & $36(24 \%)$ & $12(15 \%)$ \\
\hline $50-59$ & $26(12 \%)$ & $6(9 \%)$ & $20(13 \%)$ & $14(17 \%)$ \\
\hline 60 and older & $6(3 \%)$ & $4(6 \%)$ & $2(1 \%)$ & $2(2 \%)$ \\
\hline Ever, diagnosed with a mental illness (Yes) & $78(36 \%)$ & $24(37 \%)$ & $50(33 \%)$ & $26(32 \%)$ \\
\hline $\begin{array}{l}\text { Ever, Have a friend of family } \\
\text { member diagnosed with mental illness (Yes) }\end{array}$ & $178(83 \%)$ & $52(81 \%)$ & $118(77 \%)$ & $70(85 \%)$ \\
\hline $\begin{array}{l}\text { How knowledable are you about mental illness? } \\
\text { (very knowledgable) }\end{array}$ & $152(71 \%)$ & $54(84 \% 6)$ & $98(65 \%)$ & $56(68 \%)$ \\
\hline $\begin{array}{l}\text { Do you believe so meo ne can be born with } \\
\text { a mental illness (yes)? }\end{array}$ & $164(77 \%)$ & $48(75 \%)$ & $116(77 \%)$ & $61(74 \%)$ \\
\hline N'Other' group includes Nursing students & & & & \\
\hline
\end{tabular}

Overall community psychology students $(M=2.93, S D=0.25)$ had significantly more compassion and empathy (Benevolence) towards individuals with mental illness as compared to their 'other' graduate student $(M=2.79 ; S D=0.23)$ counterparts $(t=-3.88 ; p<0.05)$. On the other hand 'other' graduate students $(M=2.93 ; S D=0.26)$ had significantly more acceptance toward deinstitutionalization of those with mental illness and also having mental health facilities in the community (Community Mental Health Ideology) as compared to community psychology students $(M=2.85 ; S D=0.28)(t=1.98 ; p=0.04)$. There was no difference between the subscales of Authoritarian or Social restrictiveness between these two groups.

When comparing community psychology student with only nursing students; community psychology students had significantly more Benevolence $(M D=0.17 ; p<0.05)$ and less stigma on Social Restrictiveness $(M D=0.11 ; p=0.006)$ as compared to their graduate nursing student counterparts. On the other hand, the nursing graduate students had significantly less stigma than community psychology students around Community Mental Health Ideology $(M D=0.13 ; p=0.010)$. There was no difference in Authoritarian between these two groups.

Table 2: Group comparisons of CAMI domains 


\begin{tabular}{|c|c|c|c|c|}
\hline CAMI results (mean) & Community Psychology & Other & t-score & p-value \\
\hline Authoritarian (Higher more stigma) & 2.78 & 2.72 & 1.38 & 0.17 \\
\hline Benevolence (Higher less stigma) & 2.93 & 2.79 & 3.88 & $<0.05^{\circ}$ \\
\hline Social Restrictiveness (Higher more stigma) & 2.71 & 2.78 & 1.96 & $0.05^{*}$ \\
\hline Community Menta I Health Idealogy (Higher less stigma) & 2.85 & 2.93 & 1.98 & $0.05^{*}$ \\
\hline \multicolumn{5}{|l|}{ - Independent sample t-tests $p<0.05$} \\
\hline CAMI results (mea $n$ ) & Community Psychology & Nursing & t-score & p-value \\
\hline Authoritarian (Higher more stigma) & 2.78 & 2.7 & 1.78 & 0.076 \\
\hline Benevolence (Higher less stigma) & 2.93 & 2.76 & 4.16 & $<0.05^{\circ}$ \\
\hline Social Restrictiveness (Higher more stigma) & 2.71 & 2.81 & 2.77 & $<0.05^{*}$ \\
\hline Community Mental Health Idealogy (Higher less stigma) & 2.85 & 2.97 & 2.62 & $0.01^{*}$ \\
\hline - Inde pendent sample t-tests $p \leq 0.05$ & & & & \\
\hline
\end{tabular}

Additionally, we looked at the difference between community psychology students just entering the program ( $\leq 30$ credits completed) and those leaving the program ( $>30$ credits completed) and we found no significant difference in any of the four subscales.

We also explored how individual knowledge and personal experience with mental illness impacts students' attitudes. Overall, respondents who indicated that they were 'very knowledgeable about mental illness' indicated significantly less pessimistic attitudes (Authoritarian) than those that indicated they were 'not very knowledgeable' (MD=0.05, $\mathrm{p} \leq 0.05)$

Those who indicated that they had 'ever, had a family member or friend diagnosed with a mental illness' $(M=2.72)$ showed significantly less pessimistic attitudes (Authoritarian) and a greater level of acceptance toward deinstitutionalization (Community Mental Health Ideology) than those who indicated that they 'never, knew someone diagnosed with a mental illness' (Authoritarian; $M D=0.07 ; p \leq 0.05$; Community Mental Health Ideology; MD=0.08).

\section{Discussion}

Overall, our data suggests that stigma towards individuals with mental illness exists, even among health care professionals in training, such as community psychologists and nurses that are on the front lines caring for these individuals. Our findings are similar to others who have looked a stigma in nurses and counselors ${ }^{6,12}$.

Community psychology students seem to have a high level of empathy and compassion for individuals with mental illnesses, even more so than their nursing counterparts. These are promising results given that the community psychology graduate programs goal is to encourage the exploration of individual stigma associated with individuals diagnosed with mental illness.

Interestingly when comparing other' graduate students, nursing students and community psychology student the community psychology students had more stigma around deinstitutionalization of those with mental illness and having mental health facilities in the community (Community Mental Health Ideology). 
This is an interesting and perplexing finding. It would be interesting to explore further but it could be hypothesized that since students in community psychology are often employed in these types of institutions, they see the need for these types of institutions throughout the community.

Additionally, knowing someone with a diagnosis of a mental illness or even a perceived greater knowledge of mental illness seemed to significantly decrease students' pessimistic attitudes and increase their acceptance of people with mental illness in the community. Research has suggested that more education and knowledge of persons diagnosed with mental illness will lead to an overall better understanding of mental illness are less likely to have stigma and can decrease negative stereotypes ${ }^{13,14}$. Several studies have shown that participation in education programs specific to mental illness can lead to decreased stigma as well ${ }^{5,13-17}$.

This study had several limitations that diminishes the generalizability of the results such as a small sample of graduate students from a small, local university. We also were only able to receive responses from $36 \%$ of the graduate students. Even with these limitations, we were able to further add to the literature around stigma of people diagnosed with mental health disorders within health care professionals in-training, specifically community psychologist. It is our hope that we can use these data to help inform future standalone professional development, internship opportunities or by embedding curriculum into existing classes.

\section{References}

1. National Alliance on Mental IIIness (NAMI) (2019). Mental Health by the Numbers. Retrieved on April 3, 2020; https://www.nami.org/Learn-More/Mental-Health-By-the-Numbers

2. Byrne, P. (2000). Stigma of Mental Illness and Ways of Diminishing it. Advances in Psychiatric Treatment. Vol 6. 65-72.

3. Smith, A., \& Cashwell, C. (2011). Social Distance and Mental Illness: Attitudes Among Mental Health and Non-Mental Health Professionals and Trainees. The Professional Counselor. Vol 1. No 1. 13-20.

4. Mirabi M. Weinman ML. Magnetti SM, et al. (1985). Professional attitudes toward the chronic mentally ill. Hosp Community Psychiatry. 36:404-405. 
5. Keane M. Contemporary beliefs about mental illness among medical students: implications for education and practice. Acad Psychiatry. 1990;14:172-177.

6. Boysen \& Vogel. (2008). The Relationship Between Level of Training, Implicit Bias, and Multicultural Competency Among Counselor Trainees. Training and Education in Professional Psychology. Vol. 2, No. $2,103-110$.

7. Diaz-Lazaro, C. M., \& Cohen, B. B. (2001). Cross-cultural counseling training. Journal of Multicultural Counseling and Development, 29, 41-56.

8. Peris, T., Teachman, B., \& Nosek, B. (2008). Implicit and Explicit Stigma of Mental Illness Links to Clinical Care. The Journal of Nervous and Mental Disease. 196(10).

9. Taylor, M. Dear, M. (1981), "Scaling Community Attitudes Toward the Mentally III” Schizophrenia Bulletin, 7(2), 225-240

10. IBM Corp. Released 2017. IBM SPSS Statistics for Windows, Version 25.0. Armonk, NY: IBM Corp.

11. Alverno College Website, Community Psychology accessed January 9, 2020.

12. Al-Awadhi A, Atawneh F, Alalyan MY, Shahid AA, Al-Alkhadhari S, Zahid MA. Nurses' attitude towards patients with mental illness in a general hospital in Kuwait. Saudi J Med Med Sci 2017;5:31-7.

13. Corrigan P. ; Watson A. Understanding the impact of stigma on people with mental illness. World Psychiatry 1:1. February 2002.

14. Corrigan PW, Edwards A, Green A et al. Prejudice, social distance, and familiarity with mental illness. Schizophr Bull 2001;27:219-25. 
15. Brockington I, Hall P, Levings $\mathrm{J}$ et al. The community's tolerance of the mentally ill. Br J Psychiatry 1993;162:93-9.

15. Morrison JK, Cocozza JJ, Vanderwyst D. An attempt to change the negative, stigmatizing image of mental patients through brief reeducation. Psychol Rep 1980;47:334.

16. Lyons M. Ziviani J. Stereotypes, stigma, and mental illness: learning from fieldwork experiences. Am J Occup Ther. 1995;49:1002-1008.

17. Scott DJ. Phillip AE. Attitudes of psychiatric nurses and patients. Br J Med Psychol. 1985;58:169173.

\section{Competing Interests}

The authors have no conflict of interest. 